\title{
Effect of Crushed Glass Cullet Sizes on Physical and Mechanical Properties of Red Clay Bricks
}

\section{Patricia Ponce Peña, ${ }^{1}$ María Azucena González Lozano, ${ }^{1}$ Alicia Rodríguez Pulido, René Homero Lara Castro, ${ }^{1}$ Zoe V. Quiñones Jurado, ${ }^{2}$ Juan Carlos Pérez Medina, ${ }^{3}$ Martha Emilia Poisot Vázquez, ${ }^{4}$ and Axel Villavicencio Torres ${ }^{5}$}

\author{
${ }^{1}$ Facultad de Ciencias Químicas, Universidad Juárez del Estado de Durango, Av. Veterinaria S/N, Circuito Universitario, \\ 34120 Durango, DGO, Mexico \\ ${ }^{2}$ Innovación y Desarrollo en Materiales Avanzados A. C., Grupo POLYnnova, Carr. San Luis Potosí-Guadalajara 1510, Nivel 3 , \\ Local 12, Lomas del Tecnológico, 78211 San Luis Potosí, SLP, Mexico \\ ${ }^{3}$ Mabe, Manzana 10 eje 128 and Blvd. CFE, Zona Industrial, 78395 San Luis Potosí, SLP, Mexico \\ ${ }^{4}$ Universidad del Papaloapan, Campus Tuxtepec, C. Circuito Central No. 200, Col. Parque Industrial, 38301 Tuxtepec, OAX, Mexico \\ ${ }^{5}$ Universidad del Papaloapan, Campus Loma Bonita, Av. Ferrocarril S/N, Ciudad Universitaria, 68400 Loma Bonita, OAX, Mexico
}

Correspondence should be addressed to María Azucena González Lozano; magl62001@yahoo.com.mx

Received 17 June 2016; Revised 14 October 2016; Accepted 27 October 2016

Academic Editor: Wei Zhou

Copyright ( $) 2016$ Patricia Ponce Peña et al. This is an open access article distributed under the Creative Commons Attribution License, which permits unrestricted use, distribution, and reproduction in any medium, provided the original work is properly cited.

\begin{abstract}
This study reports the effect of clear waste glass from bottles added on 20 to $30 \mathrm{wt} . \%$ and variable particle size $(<500,<300$, and $<212 \mu \mathrm{m}$ ), into clay mixtures for the handmade brick manufacturing process. The bricks were manufactured with mixtures of clay, crushed glass, and water in different proportions, homogenized, casted in wooden molds, air-dried at room temperature for $72 \mathrm{~h}$, and sintered at $1000^{\circ} \mathrm{C}$ for $12 \mathrm{~h}$. Total shrinkage, water absorption, compressive strength, microstructure, and phase composition are discussed with respect to glass content and its particle size. The results indicate that increasing the content of glass and decreasing its particle size enhanced significantly the brick properties of water absorption and compressive strength by up to $18.5 \%$ and $6.8 \mathrm{MPa}$, for bricks with $30 \mathrm{wt} \%$ and particle size lower than $212 \mu \mathrm{m}$. It is proposed that decreasing the glass particle size its surface area increases allowing easier melting of glass by lower energy consumption, reducing porosity and enhancing brick properties.
\end{abstract}

\section{Introduction}

The problems related to waste generation are becoming more and more significant in relation to the improvement of economic conditions and the progress of industrial development, Karamberi et al. [1]. As a consequence, the increasing amount of industrial wastes such as plastics, glass (cullet), and grogs (fired clays) has brought environmental problems to our society. According to Loryuenyong et al. [2], the disposal of these wastes is one of the areas that have received a lot of attention and the benefits of recycling waste are both environmental and economic.

Waste glass or cullet from bottles and windows mainly is a waste material classified as a nondangerous by the European
Waste Catalogue (EWC), [3] with economical potential. The most common uses of cullet include its application as an additive in glass reforming due to its low softening temperature [3]; as a promising alternative cementitious material in cement and concrete production [4]; in road work applications, [5], in glass foam production [6,7]; and in the porcelain stoneware tile and brick industries [8-11].

On the other hand, fired clay bricks are building materials used since the ancient times to our days; however, it is required to improve its quality for use in modern constructions. The fabrication of clay bricks includes a sintering stage that involves shrinkage of clay bodies at high temperature and due to the high demand of energy in this process, additives called fluxes are often added. The introduction of cullet into 


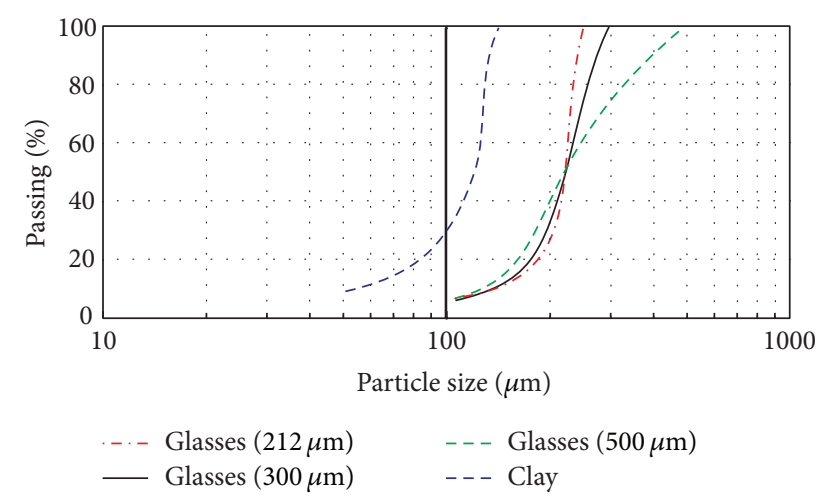

Figure 1: Particle size analysis of waste glass and clay.

the batch is promising for decreasing energy consumption and fuel saving since cullet could acts as flux inducing the vitrification of bricks delivering higher mechanical resistance, higher density, and less water absorption [2, 8-11] to the final material.

In Mexico, the production of clay bricks is a manual process of mixing, casting drying, and sintering. The last stage is performed in traditional ovens made of stacked clay bricks forming a chamber; unfortunately no insulation is provided and consequently during sintering the heat is partially lost. In this sense, mixing cullet and clay is a very promising way to reduce the sintering temperature in order to produce bricks of quality for modern building constructions. This work studied the effect of both the cullet particle size and the concentration on the performance of the typical fired clay bricks produced in Mexico by measuring the mechanical resistance, water absorption, and shrinkage of the final samples. Also, the materials' microstructure was studied.

\section{Materials and Methods}

2.1. Preparation of Raw Materials. The traditional clay used for brick production in Durango, Mexico, was also used in this work. Waste glass (clear bottles of soda-lime-silica glass) was washed, crushed in a ceramic ball mill, and sieved at three maximum particle sizes by mesh of $500 \mu \mathrm{m}, 300 \mu \mathrm{m}$, and $212 \mu \mathrm{m}$. The particle size range determination was carried out for cullet and clay using sieve analysis, and the results were plotted and are shown in Figure 1.

Likewise, Table 1 presents chemical analyses carried out on clay and glass. Also, the clay and cullet phases composition was determined by X-ray diffraction (XRD, Philips X'Pert$\mathrm{MPD})$ using $\mathrm{Cu}-\mathrm{K} \alpha$ radiation. The main crystalline phases present in clay were quartz, tridymite, and albite, Figure 2.

2.2. Specimen Preparation. Test specimens were prepared by mixing the raw materials (clay and glass) according to the information in Table 2. Each batch of specimens was manually mixed until homogeneity was ensure and then $20-$ $25 \mathrm{wt} \%$ of water was added and mixed to obtain a plastic paste, which was casted into rectangular molds of $190 \mathrm{~mm} \times$
TABLE 1: Chemical composition of raw materials.

\begin{tabular}{lcc}
\hline Composition & Clay (wt\%) & Waste glass (wt\%) \\
\hline $\mathrm{SiO}_{2}$ & 54.54 & 68.48 \\
$\mathrm{Al}_{2} \mathrm{O}_{3}$ & 20.95 & 8.52 \\
$\mathrm{Fe}_{2} \mathrm{O}_{3}$ & 3.060 & 0.45 \\
$\mathrm{MgO}$ & 0.580 & 0.35 \\
$\mathrm{CaO}$ & 0.680 & 9.98 \\
$\mathrm{ZnO}$ & 0.004 & - \\
$\mathrm{Na}_{2} \mathrm{O}$ & 12.78 & 11.61 \\
$\mathrm{~K}_{2} \mathrm{O}$ & 1.390 & 0.56 \\
\hline
\end{tabular}

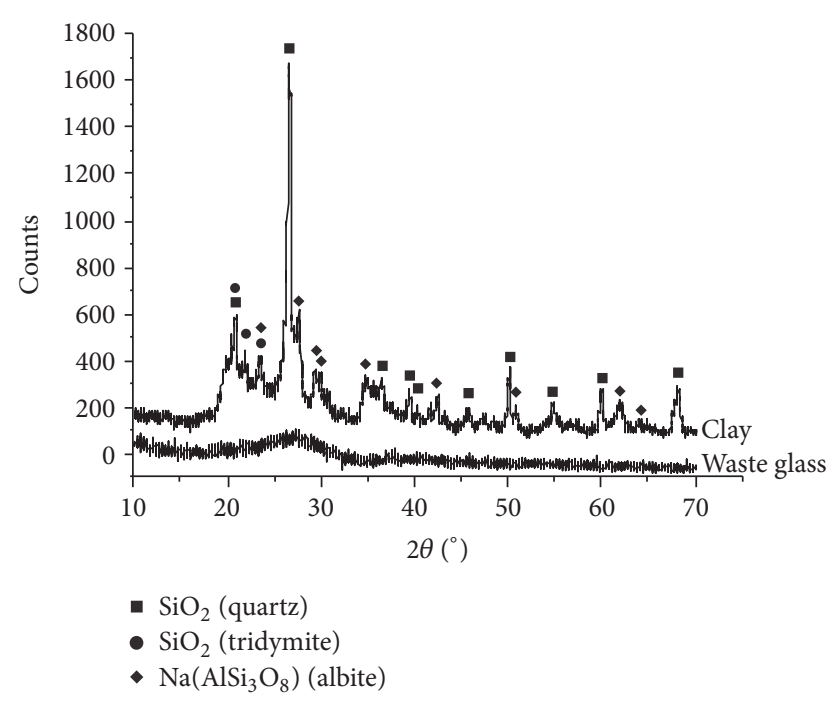

FIGURE 2: X-ray analyses for waste glass and clay.

TABLE 2: Composition of bricks produced.

\begin{tabular}{lcc}
\hline Composition & Waste glass $($ weight $\%)$ & Particle size $(\mu \mathrm{m})$ \\
\hline TB & 0 & - \\
TB20-35 & 20 & $<500$ \\
TB20-50 & 20 & $<300$ \\
TB20-70 & 20 & $<212$ \\
TB25-35 & 25 & $<500$ \\
TB25-50 & 25 & $<300$ \\
TB25-70 & 25 & $<212$ \\
TB30-35 & 30 & $<500$ \\
TB30-50 & 30 & $<300$ \\
TB30-70 & 30 & $<212$ \\
\hline
\end{tabular}

$100 \mathrm{~mm} \times 50 \mathrm{~mm}$. The clay brick specimens were air-dried at room temperature for $72 \mathrm{~h}$ and later fired at $1000^{\circ} \mathrm{C}$ for $12 \mathrm{~h}$.

2.3. Test Methods. The compressive strength was determined using a Physical Test Solutions (FMCC-200) universal testing machine on full brick, according to ASTM C67-14 [12]. A total linear shrinkage was determined by direct measurement of specimens before drying and after firing. Water absorption 
TABLE 3: Water absorption, shrinkage, and mechanical strength results.

\begin{tabular}{|c|c|c|c|c|c|}
\hline \multirow{2}{*}{ Composition } & \multirow{2}{*}{ Water absorption (\%) } & \multicolumn{3}{|c|}{ Shrinkage (\%) } & \multirow{2}{*}{ Compressive strength (Mpa) } \\
\hline & & Length & Width & Height & \\
\hline TB & $33.6 \pm 2.2$ & $7.5 \pm 0.6$ & $7.3 \pm 0.7$ & $7.2 \pm 0.6$ & $1.8 \pm 0.25$ \\
\hline TB20-35 & $28.7 \pm 2.3$ & $8.2 \pm 1.0$ & $7.2 \pm 0.9$ & $7.8 \pm 1.1$ & $1.9 \pm 0.19$ \\
\hline TB20-50 & $26.3 \pm 1.3$ & $8.3 \pm 0.7$ & $7.4 \pm 1.1$ & $7.8 \pm 0.9$ & $2.8 \pm 0.91$ \\
\hline ТВ $20-70$ & $27.0 \pm 0.7$ & $8.6 \pm 1.1$ & $7.7 \pm 0.7$ & $6.7 \pm 0.7$ & $3.0 \pm 0.49$ \\
\hline ТВ25-35 & $25.6 \pm 2.1$ & $7.6 \pm 1.3$ & $7.4 \pm 0.7$ & $7.1 \pm 0.9$ & $3.0 \pm 0.74$ \\
\hline ТВ25-50 & $26.3 \pm 2.6$ & $7.9 \pm 0.8$ & $6.4 \pm 1.0$ & $8.3 \pm 1.1$ & $3.4 \pm 0.50$ \\
\hline TB25-70 & $20.6 \pm 1.6$ & $8.3 \pm 1.1$ & $6.9 \pm 0.9$ & $6.3 \pm 1.3$ & $3.4 \pm 0.42$ \\
\hline TB30-35 & $23.6 \pm 2.6$ & $9.9 \pm 0.9$ & $7.9 \pm 0.6$ & $8.1 \pm 0.8$ & $3.9 \pm 0.63$ \\
\hline TB30-50 & $23.7 \pm 2.4$ & $9.3 \pm 0.9$ & $7.7 \pm 0.8$ & $8.3 \pm 0.8$ & $5.4 \pm 0.47$ \\
\hline TB30-70 & $18.5 \pm 1.6$ & $9.2 \pm 1.1$ & $7.9 \pm 0.7$ & $8.3 \pm 0.7$ & $6.9 \pm 0.69$ \\
\hline
\end{tabular}

was determined using the Archimedes method mentioned in the same standard test. For microstructural analyses, fragments of fired bricks were mounted in resin, ground with $\mathrm{SiC}$ sand paper, polished with alumina solution of $1 \mu \mathrm{m}$, and later coated with graphite for observation under a scanning electron microscopy (SEM, Philips XL-30 ESEM). Likewise, the crystalline phases for all of the brick samples were analyzed by X-ray diffraction (XRD, Philips X'Pert-MPD) using $\mathrm{Cu}-\mathrm{K} \alpha$ radiation, with the peaks identified by means of the International Centre for Diffraction Data (ICDD) standard database.

\section{Results and Discussion}

Table 3 shows the water absorption, total shrinkage and mechanical strength results of the traditional bricks (TB) produced. All the compositions with glass show lower water absorption than the TBs; it can be seen that water absorption has decreased from $28.7 \%$ in traditional bricks to $18.5 \%$ in bricks with $30 \%$ of cullet with particle size smaller than $212 \mu \mathrm{min}$ accordance with Loryuenyong et al. results. [2]. It is suggested that increasing the cullet content promotes the formation of liquid-phase of glass that contributes reducing the voids and pore volume into the material; as a consequence, the water absorption rate of $\mathrm{TB}$ added with cullet is lower than the normal TB. Likewise, by increasing the glass-specific surface area, particles become more reactive, allowing easier melting of glass by lower energy consumption; when the glass is melt about $500^{\circ} \mathrm{C}$ [13], it can fill the voids into the material giving place to lower porosity and lower water incoming than the TB.

In ceramic materials, linear shrinkage is directly proportional to the degree of sintering; however, large linear shrinkage will increase the risk of fractures and cracks in the bricks. According to the results, the addition of glass decreased porosity which also affected the shrinkage of the material. So the shrinkage was increased as the densification of the brick was increased too. According to the results (Table 3), the TBs with $30 \%$ wt of cullet show the highest value of linear shrinkage, and similar results are obtained by other working groups $[2,9,10]$.
The compressive strength is a mechanical property measured to qualify the brick performance. It has great importance due to the fact that higher compressive strength improves flexure and resistance to abrasion and furthermore this property is easy to evaluate [9]. In this sense, the results shown in Table 3 allow seeing that the introduction of cullet improved compressive strength with respect to TB. The results revealed also that compressive strengths were in the range of 1.8 to $6.8 \mathrm{MPa}$ increasing with the decrease in the particle size of cullet. Such behavior is clear from the view of glass melting enhanced when the particle size is reduced allowing the filling of voids into the material.

The data of water absorption and compressive strength are related to each other in the opposite way; the water absorption percentage is the lowest in TB30-70, and when compared to $\mathrm{TB}$ it is just $55 \%$, and the compressive strength is 3.8 times that of TB. The linear shrinkage must be related to the density of the samples; when the sample shrinks more it is expected that the sample will show high density enhancing the compressive strength of the material. Taking into account that bricks were produced in a traditional oven that shows differences in firing temperature in several zones of the chamber could significantly affect the properties of bricks [10], it is proposed that during the sintering stage there was a fluctuation of the temperature, and for this reason bricks with low compressive strength were obtained. On the other hand, the Mexican standards NMX-C-037-ONNCCE [14] and NMX-C-404-ONNCCE [15] establish that water absorption and compressive strength on fired clay bricks should be a maximum of $21 \%$ and minimum of $6 \mathrm{MPa}$, respectively. According to the above, only the mixture with $30 \%$ of glass and a particle size of less than $212 \mu \mathrm{m}$, TB3070 , satisfies the standard to be used as building material in Mexico. Likewise, Mexican standards do not establish a maximum valor of shrinkage. However, other authors have reported values of drying shrinkage between 5.35 and $6.45 \%$ [16], while Zhang [11] indicate that bricks with good quality should have values of firing shrinkage below $8 \%$. Therefore, all the bricks manufactured in this work presented a total shrinkage (drying and firing shrinkage) less than 10\%; the bricks were crack-free making them useful for the established purpose. 


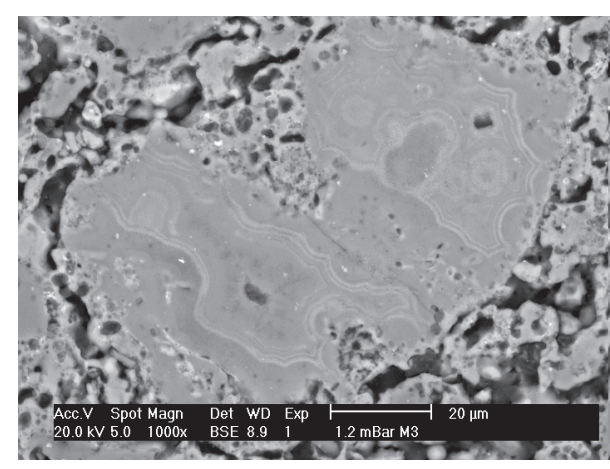

(a)

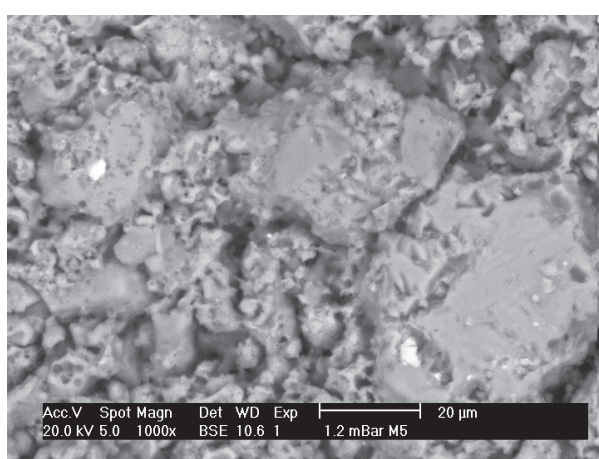

(c)

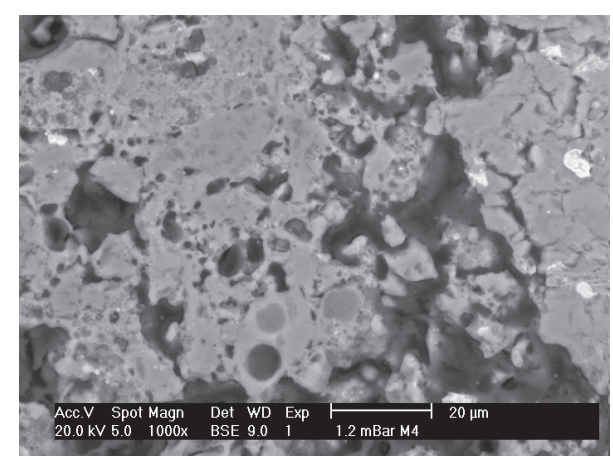

(b)

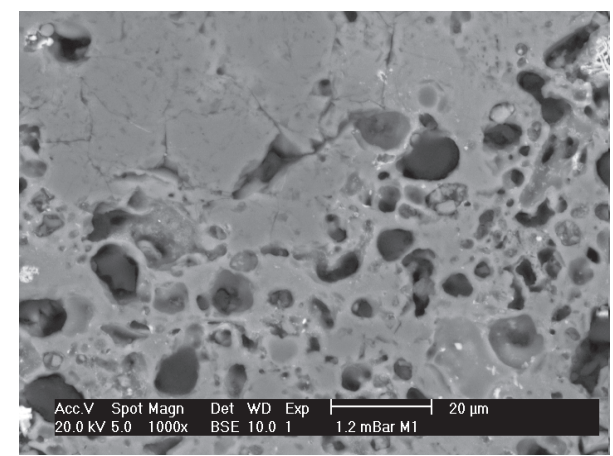

(d)

FIGURE 3: SEM analyses for (a) brick without glass (TB), (b) brick with 30\% glass and particle size smaller than 500 $\mu \mathrm{m}$ (TB30-35), (c) brick with $30 \%$ glass and particle size smaller than $300 \mu \mathrm{m}$ (TB30-50), and (d) brick with 30\% glass and particle size smaller than 212 $\mu \mathrm{m}$ (TB30-70).

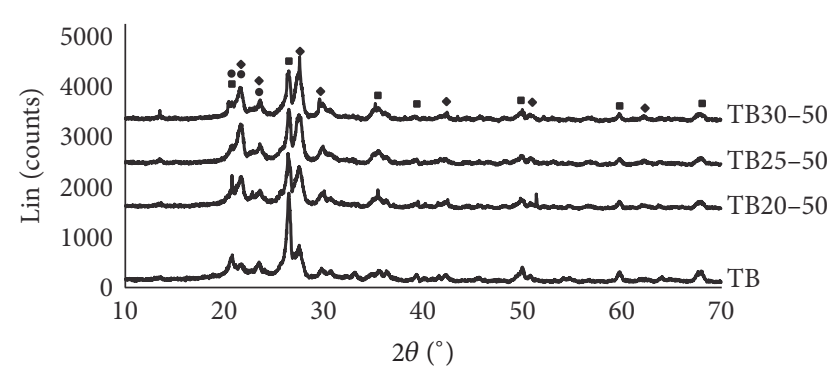

- $\mathrm{SiO}_{2}$ (quartz)

- $\mathrm{SiO}_{2}$ (tridymite)

- $\mathrm{Na}\left(\mathrm{AlSi}_{3} \mathrm{O}_{8}\right)$ (albite)

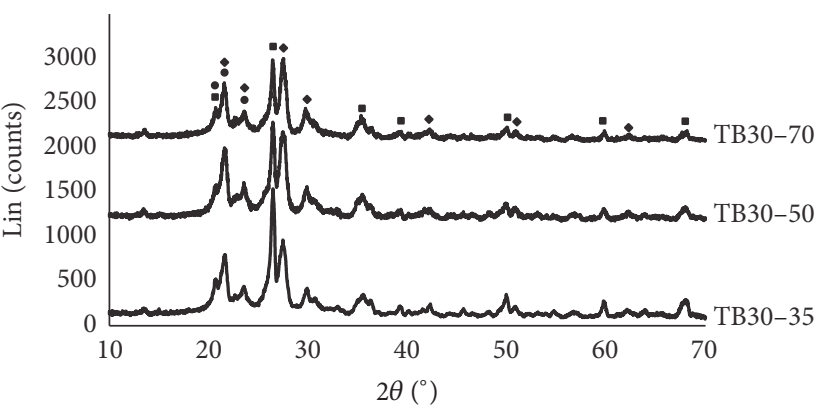

- $\mathrm{SiO}_{2}$ (quartz)

- $\mathrm{SiO}_{2}$ (tridymite)

- $\mathrm{Na}\left(\mathrm{AlSi}_{3} \mathrm{O}_{8}\right)$ (albite)

(a)

(b)

FIGURE 4: X-ray diffraction patterns of some obtained bricks: (a) effect of glass content increases and (b) effect of glass particle size reduction.

Figure 3 shows several SEM micrographs of the fired clay bricks with $30 \%$ of glass content with different particle size. It can be observed that the decrease of glass particle size contributed to the formation of a microstructure with lower content of pores and it is also noteworthy the presence of a glassy phase in the bricks with $30 \%$ of cullet and particle size smaller than $212 \mu \mathrm{m}$. It is proposed that this liquid glassy phase acts as a binder which promotes a more compact microstructure with less pores, voids, and fractures delivering better physical and mechanical properties to the material, which is consistent with the data of water absorption, linear shrinkage, and compressive strength.

On the other hand, Figure 4 shows the XRD results of some bricks samples. X-ray diffraction patterns show the presence of different phases that are identified as: quartz $\mathrm{SiO}_{2}$ (PDF 01-070-3755), tridymite $\mathrm{SiO}_{2}$ (PDF 00-016-0152), and albite $\mathrm{Na}\left(\mathrm{AlSi}_{3} \mathrm{O}_{8}\right.$ ) (PDF 01-078-1995). In Figure 4(a), it can be noticed that, by increasing the content of glass in bricks, the intensity of the peak of the quartz phase decreases while the intensity of the peak of tridymite phase increases; 
the same effect can be appreciated for compositions with the same content of glass but with reduced particle size, Figure 4(b). It is proposed that, at high temperature, most of the silica in quartz phase contained in the bricks remains unreacted but some amount of quartz can be transformed into tridymite. It is also important to notice that the effect of increasing the amount of cullet into the TB is increasing the intensity of albite phase; it is proposed that there is diffusion of $\mathrm{Na}^{+}$from liquid glass toward albite and silica phases promoting the formation of more albite. It is assumed that matter transport during sintering occurs by surface diffusion, lattice diffusion, boundary diffusion on the surface, grain boundary, and dislocations of the particles [17].

\section{Conclusions}

In the current study, handmade bricks for construction were obtained (without cracks or fractures). The common composition of such bricks was partially replaced by 20 , 25 , and $30 \%$ of recycled glass of variable particle size. It was demonstrated that increasing the content of glass and decreasing its particle size, in traditional mixtures for clay bricks, enhanced significantly the brick properties of water absorption and compressive strength. Likewise, according to Mexican regulations, bricks with $30 \%$ of glass and particle size smaller than $212 \mu \mathrm{m}$ can be used as building material.

\section{Competing Interests}

The authors declare that they have no competing interests.

\section{Acknowledgments}

The authors acknowledge the Mexican Program (PROFOCIE 2014) for the financial support with respect to the realization of this research. The authors would also like to thank Omar Novelo Peralta and Adriana Tejeda Cruz for technical support.

\section{References}

[1] A. Karamberi, K. Orkopoulos, and A. Moutsatsou, "Synthesis of glass-ceramics using glass cullet and vitrified industrial byproducts," Journal of the European Ceramic Society, vol. 27, no. 2-3, pp. 629-636, 2007.

[2] V. Loryuenyong, T. Panyachai, K. Kaewsimork, and C. Siritai, "Effects of recycled glass substitution on the physical and mechanical properties of clay bricks," Waste Management, vol. 29, no. 10, pp. 2717-2721, 2009.

[3] E. Furlani, G. Tonello, and S. Maschio, "Recycling of steel slag and glass cullet from energy saving lamps by fast firing production of ceramics," Waste Management, vol. 30, no. 8-9, pp. 1714$1719,2010$.

[4] C. Shi and K. Zheng, "A review on the use of waste glasses in the production of cement and concrete," Resources, Conservation and Recycling, vol. 52, no. 2, pp. 234-247, 2007.

[5] M. M. Disfani, A. Arulrajah, M. W. Bo, and R. Hankour, "Recycled crushed glass in road work applications," Waste Management, vol. 31, no. 11, pp. 2341-2351, 2011.
[6] A. S. Llaudis, M. J. O. Tari, F. J. G. Ten, E. Bernardo, and P. Colombo, "Foaming of flat glass cullet using $\mathrm{Si}_{3} \mathrm{~N}_{4}$ and $\mathrm{MnO}_{2}$ powders," Ceramics International, vol. 35, no. 5, pp. 1953-1959, 2009.

[7] H. R. Fernandes, D. U. Tulyaganov, and J. M. F. Ferreira, "Preparation and characterization of foams from sheet glass and fly ash using carbonates as foaming agents," Ceramics International, vol. 35, no. 1, pp. 229-235, 2009.

[8] T. K. Pavlushkina and N. G. Kisilenko, "Cullet use in the production of building materials," Glass and Ceramics, vol. 68, no. 5-6, pp. 162-168, 2011.

[9] N. Phonphuak, S. Kanyakam, and P. Chindaprasirt, "Utilization of waste glass to enhance physical-mechanical properties of fired clay brick," Journal of Cleaner Production, vol. 112, pp. 3057-3062, 2016.

[10] S. Maschio, E. Furlani, G. Tonello et al., "Fast firing of tiles containing paper mill sludge, glass cullet and clay," Waste Management, vol. 29, no. 11, pp. 2880-2885, 2009.

[11] L. Zhang, "Production of bricks from waste materials-a review," Construction and Building Materials, vol. 47, pp. 643655, 2013.

[12] ASTM, "Standard test method of sampling and testing brick and structural clay tile," ASTM C67-14, 2004.

[13] M. I. Ojovan, "Configurons: thermodynamic parameters and symmetry changes at glass transition," Entropy, vol. 10, no. 3, pp. 334-364, 2008.

[14] NMX-C-037-ONNCCE, Building Industry. Concrete-Blocks, Bricks or Partition Masonry Wits Units Determination of Absorbent water and Determination of Initial Absorbent, 2005.

[15] Organismo Nacional de Normalización y Certificación de la Construcción y Edificación, "Building industry-blocks, partition or bricks and masonry units for structural usespecifications and testing methods," Tech. Rep. NMX-C-404ONNCCE, 2005.

[16] Y. M. Zhang, L. T. Jia, H. Mei, Q. Cui, P. G. Zhang, and Z. M. Sun, "Fabrication, microstructure and properties of bricks fired from lake sediment, cinder and sewage sludge," Construction and Building Materials, vol. 121, pp. 154-160, 2016.

[17] W. D. Kingery, H. K. Bowen, and D. R. Uhlmann, Introduction to Ceramics, John Wiley \& Sons, New York, NY, USA, 1976. 

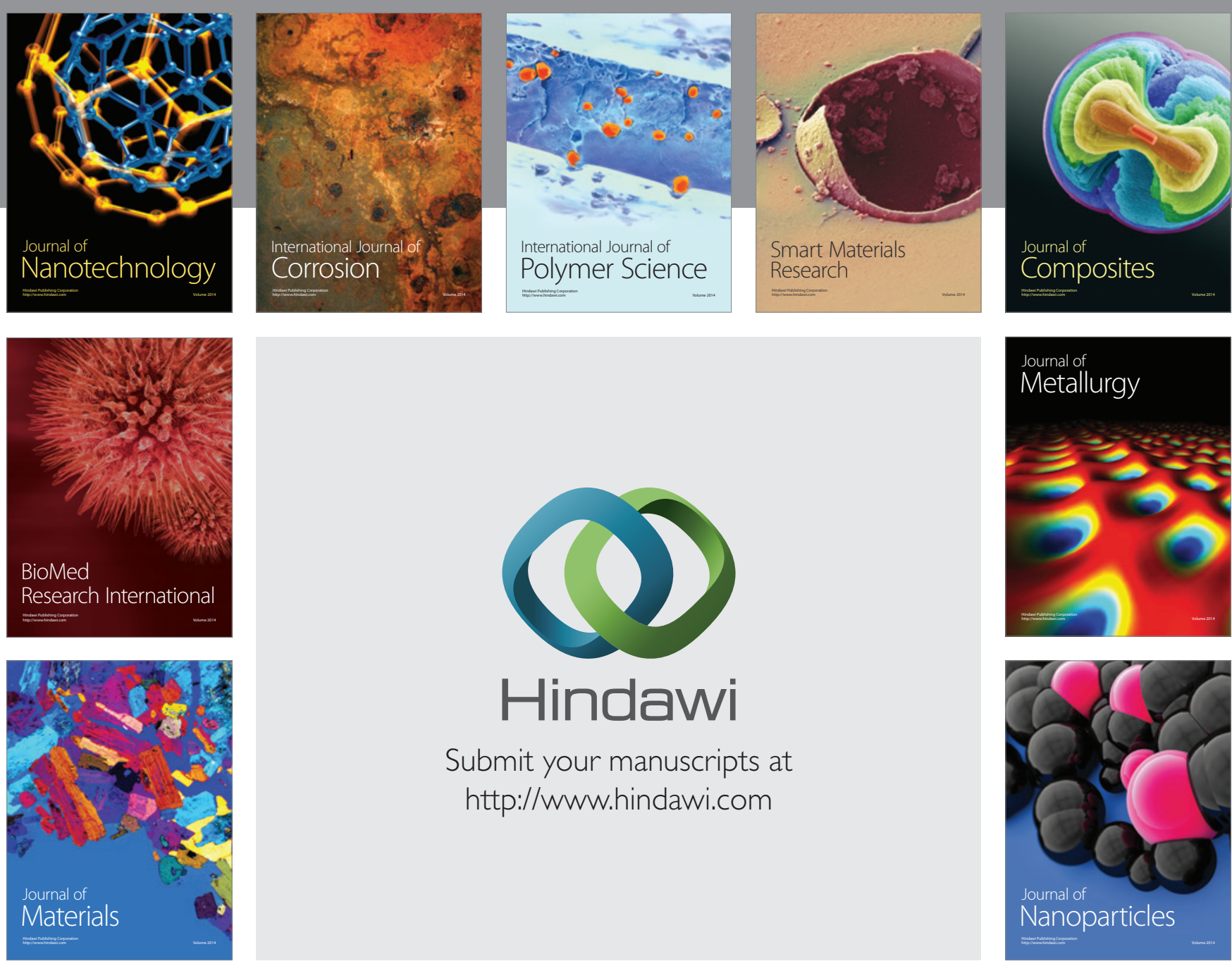

\section{Hindawi}

Submit your manuscripts at

http://www.hindawi.com

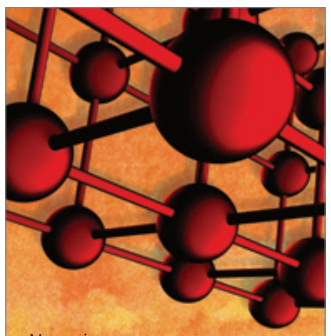

Materials Science and Engineering
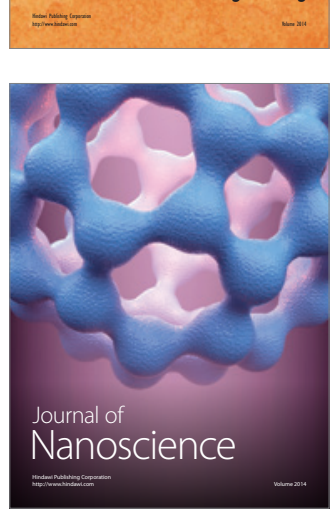
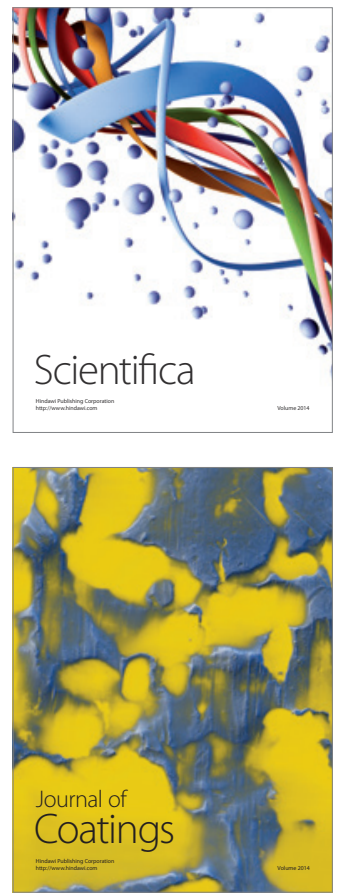
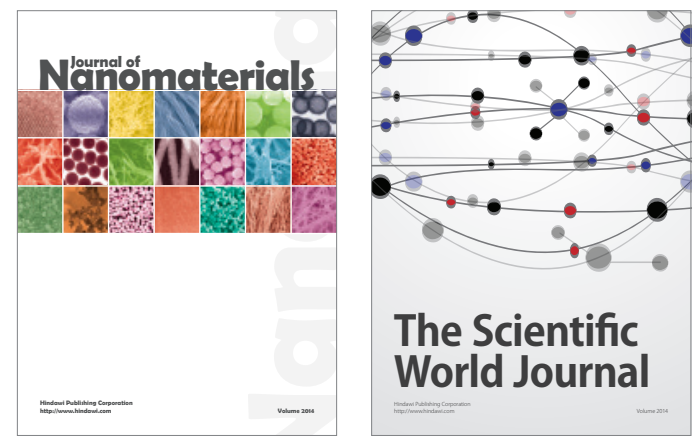

The Scientific World Journal
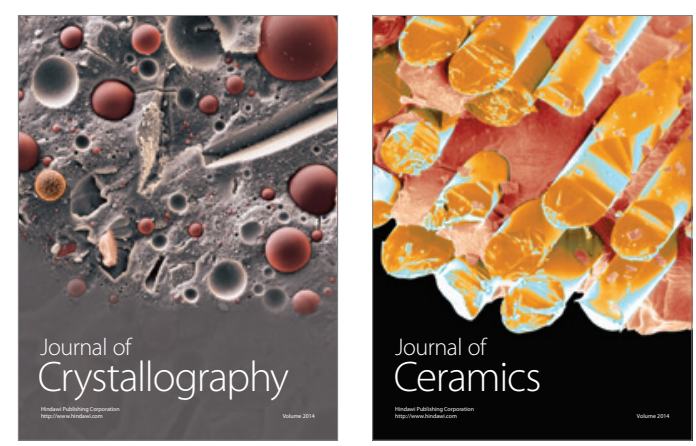
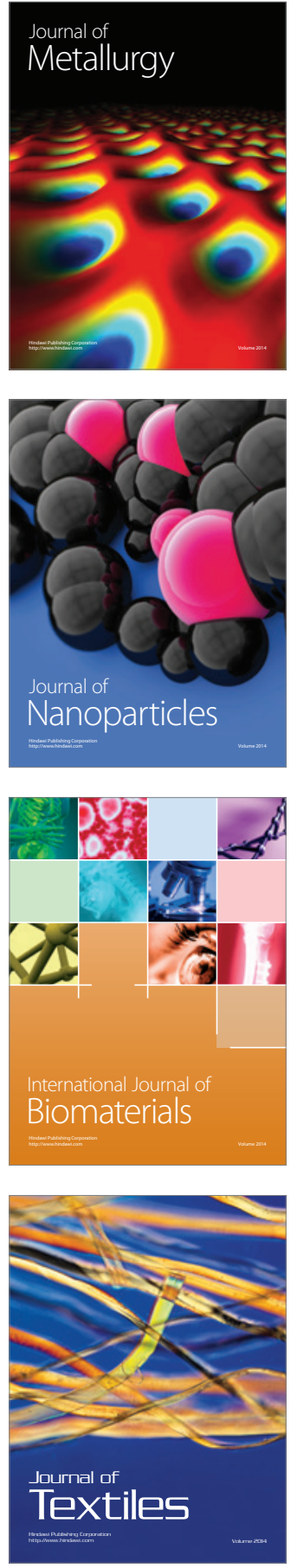